\title{
Model Predictive Controller Utilized as an Observer for Inter- Turn Short Circuit Detection in Induction Machines - Preprint Version
}

This paper was downloaded from TechRxiv (https://www.techrxiv.org).

\section{LICENSE}

CC BY 4.0

SUBMISSION DATE / POSTED DATE

$23-01-2021 / 25-01-2021$

\section{CITATION}

Şahin, İlker; Keysan, Ozan (2021): Model Predictive Controller Utilized as an Observer for Inter-Turn Short Circuit Detection in Induction Machines - Preprint Version. TechRxiv. Preprint.

https://doi.org/10.36227/techrxiv.13633376.v1

$\mathrm{DOI}$

10.36227/techrxiv.13633376.v1 


\title{
Model Predictive Controller Utilized as an Observer for Inter-Turn Short Circuit Detection in Induction Motors - Preprint Version
}

\author{
İlker Şahin, Student Member, IEEE, Ozan Keysan, Member, IEEE \\ https://ieeexplore.ieee.org/document/9310277
}

\begin{abstract}
In this paper, a novel and non-invasive stator interturn short circuit (ITSC) online detection method is presented for an induction machine (IM), driven by a two-level voltage source inverter (2L-VSI) via finite control set model predictive control (FCS-MPC). The main idea of the proposed method is to utilize the controller itself as an observer: under the presence of a fault, the distribution of inverter switching states significantly deviates from the original balanced case. Therefore, by inspecting the inverter switching vectors, which are the outcomes of the FCS-MPC routine's online optimization procedure, a stator fault can be detected efficiently. It is observed that both the zero-vector allocation over the complex plane and the allocation among the active vectors are influenced by the presence of a stator shortcircuit fault. The proposed fault detection strategy introduces little to no extra burden for processor and memory. Experimental results verify the proposed method, and inter-turn short circuits of two and three turns are confidently detected and located for a $500 \mathrm{~W}$, two-pole IM.
\end{abstract}

Index Terms-- Fault diagnosis, condition monitoring, finite control set model predictive control (FCS-MPC), inter-turn short circuit (ITSC), inverter statistics.

\section{INTRODUCTION}

$\mathrm{F}$ AULT diagnosis and condition monitoring of electrical machines are vital for industrial applications. Early detection of an incipient fault can significantly reduce both the repair cost and the downtime of the process under consideration. In mission-critical applications such as electric transportation, early fault detection abilities become even more important for increased passenger safety and system reliability. Consequently, fault diagnosis has been a significant focus of research [1]-[4].

While most of the early works in fault diagnosis research concentrate on the fault signatures of line-fed motors, recent studies consider fault detection of inverter-fed, closed-loop controlled machines [5]-[16]. Condition monitoring for closedloop controlled drive systems becomes especially interesting because the controller inherently tries to create a balanced set of phase currents even in the case of a faulted machine, covering the fault traces to a large extent [5]-[7]. Therefore, for a closedloop motor drive system, any fault detection algorithm should be assessed in conjunction with the main motor control technique. Among the previous studies mentioned as examples of fault detection with closed-loop control, field-oriented control (FOC) is considered in [5]-[13], direct torque control (DTC) in [14], [15], and model predictive control (MPC) in [16].

MPC has emerged as a promising alternative for FOC and DTC, which are today's industry standards for variable speed drives. It has drawn significant attention from the research community due to its merits, such as fast dynamic response, intuitive algorithm, and flexible structure that allows the straightforward inclusion of system constraints and converter nonlinearities [17]-[21]. MPC is the chosen motor drive technique in this study since its intrinsically fast and flexible control structure lends itself to be suitable for the proposed fault detection algorithm.

Induction machine (IM) faults can be classified into three groups; stator, rotor, and bearing faults. Stator faults, which account for $21 \%$ of the total faults [22], [23], usually start as inter-turn short circuits (ITSCs), which arise from the loss of insulation in the stator winding and quickly evolve into complete phase to phase or phase to ground faults. Therefore, a fast and reliable determination of an incipient short circuit in the stator winding is necessary.

In this paper, we suggest a new algorithm to detect stator ITSC faults, including the fault location, for an IM driven by finite control set model predictive control (FCS-MPC). The algorithm works as simple extensions to the standard FCS-MPC routine. The fundamental principle of the proposed algorithm for fault detection is straightforward: an IM without any fault is a balanced system. Therefore, considering a closed-loop speed controller, the voltage vectors that are commanded by the controller are expected to exhibit a balanced distribution. An ITSC acts as a disturbance to this balanced system; hence, any unexpected allocation of the voltage vectors would indicate the presence of an ITSC. While the proposed approach for fault detection can be generalized for other closed-loop control strategies, its implementation alongside MPC is intuitive. Just by observing the outcomes of the optimization routine of the predictive control algorithm, the relative distribution of the voltage vectors can be easily examined, and any unexpected deviation can be detected. As there is no perfectly balanced

The authors are with the Electrical and Electronics Engineering Department of Middle East Technical University, Ankara, Turkey. İ. Şahin is with Aselsan Inc. (e-mail: ilkersahin@aselsan.com.tr; keysan@metu.edu.tr). 
IMPORTANT NOTE: THIS PAPER IS THE ACCEPTED (NON-EDITED) VERSION OF THE ORIGINAL STUDY TO APPEAR IN IEEE

THE PUBLISHED PAPER. COPYRIGHTS BELONG TO IEEE. https://ieeexplore.iee.org/document/9310277

machine and also considering the influence of noise on the controller action, an ideal balance condition cannot be observed for practical systems. However, variations among the voltage vectors for a healthy IM are significantly less than those of an IM with an ITSC, which is verified by the experimental results.

A methodology for fault detection, which relies on examining the inverter switching statistics for any abnormal distribution, is previously proposed in [9]. Although the underlying principle adopted for fault detection is similar, there exist several differences regarding both the motor control strategy and the figures that indicate fault existence. An additional predictive current control (PCC) routine is implemented alongside FOC in [9], without any detailed description of the control scheme. The method to interpret the switching vector distribution is also different. Furthermore, the influence of FCS-MPC related parameters, such as the weighting factor $(\lambda)$ and the sampling frequency, on the fault detection performance is presented in this study.

The remainder of this paper is organized as follows. In section II, the mathematical model of an IM with an ITSC fault is constructed. In section III, the control routine of the FCSMPC is presented. The influence of an ITSC on the current waveforms is examined in section IV, for both the open-loop and closed-loop operations. The proposed fault detection algorithm is described in section $\mathrm{V}$, and the experimental results are provided to prove its effectiveness. A series of discussions and a comparison of the proposed method with respect to the previous studies are also provided in section V. Finally, the paper concludes with section VI.

\section{InduCtion Machine Model With a Stator SHORT- Circuit FAulT}

An IM with an inter-turn short circuit (ITSC) is shown in Fig. 1, where the fault is arbitrarily assumed in phase A. The ratio of the number of shorted turns to the total number of turns in one phase $\left(N_{f} / N\right)$ is defined as $\mu$. ITSC is modeled as the fault current $I_{f}$ flowing over the fault resistance $R_{f}$. Among various modeling studies reported so far [24]-[27], the formulation presented in [24] is adopted with the assumption of the linear distribution of the leakage inductance $L_{l s}$, such that the leakage inductance of the shorted turns is equal to $\mu L_{l s}$. With the complex vector notation from the stationary reference frame $\left(f_{\alpha \beta}=f_{\alpha}+j f_{\beta}\right)$, state-space model of an IM with an ITSC can be described by

$$
\begin{gathered}
V_{s}=R_{s} I_{s}+\frac{d \Psi_{s}}{d t}-\frac{2}{3} \mu I_{f} R_{s} \\
V_{r}=R_{r} I_{r}+\frac{d \Psi_{r}}{d t}-j w_{e} \Psi_{r} \\
\Psi_{s}=L_{s} I_{s}+L_{m} I_{r}-\frac{2}{3} \mu I_{f} L_{s} \\
\Psi_{r}=L_{m} I_{s}+L_{r} I_{r}-\frac{2}{3} \mu I_{f} L_{m} \\
\mathrm{~T}_{e}=\frac{3}{2} p L_{m}\left(I_{s \beta} I_{r \alpha}-I_{s \alpha} I_{r \beta}\right)-\frac{3}{2} \mu L_{m} I_{f} I_{r \alpha}
\end{gathered}
$$

$$
J \frac{d \omega_{m}}{d t}=\mathrm{T}_{e}-\mathrm{T}_{l}
$$

where $V, I$, and $\Psi$ represent voltage, current, and flux linkage complex vectors, $R$ and $L_{m}$ represent the series resistance and the magnetizing inductance, respectively. Subscripts $s$ and $r$ indicate stator and rotor quantities. The inductances $L_{s}$ and $L_{r}$ compose of leakage and magnetizing terms, such that $L_{s}=$ $L_{l s}+L_{m}$ and $L_{r}=L_{l r}+L_{m}$ where $L_{l s}$ and $L_{l r}$ represent leakage inductances. $\mathrm{T}_{e}$ and $\mathrm{T}_{l}$ are electromagnetic and load torque, $\omega_{m}$ is rotor angular speed, $\omega_{e}$ is rotor angular frequency, and $p$ is the number of pole pairs.

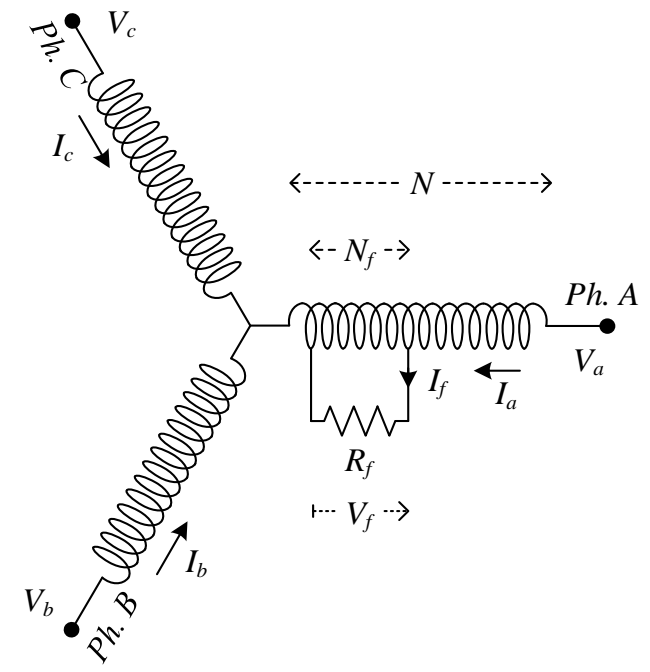

Fig. 1. The three-phase stator winding of an IM with an ITSC fault on its phase A.

Voltage equations for the shorted turns can be expressed by (7)-(8), where $V_{f}$ is the voltage and $\Psi_{f}$ is the flux linkage across the shorted turns.

$$
\begin{gathered}
V_{f}=R_{f} I_{f}=\mu R_{s}\left(I_{s \alpha}-I_{f}\right)+\frac{d \Psi_{f}}{d t} \\
\Psi_{f}=\mu L_{l s}\left(I_{s \alpha}-I_{f}\right)+\mu L_{m}\left(I_{s \alpha}+I_{r \alpha}-\frac{2}{3} \mu I_{f}\right) \\
\Psi_{f m}=\mu L_{m}\left(I_{s \alpha}+I_{r \alpha}-\frac{2}{3} \mu I_{f}\right)
\end{gathered}
$$

Zero sequence components, which would arise in the presence of an ITSC, are not included here with the assumption of floating neutral operation. It should be noted that a precise and complete characterization of an ITSC fault requires detailed modeling of the winding and slot geometry, including the magnetic properties of the core material. However, the presented model is favorable when the main motivation is to explain the fault's influence for the purpose of fault diagnostics. The equivalent circuits for an IM with ITSC and the faulty turns are drawn in Fig. 2. $\Psi_{f m}$ is defined as (9).

The shorted turns cause the fault current $I_{f}$, which may be much higher than the rated current, depending on the value of fault resistance $R_{f}$. This high current can quickly cause a hotspot in the winding and may develop into permanent damage if 
IMPORTANT NOTE: THIS PAPER IS THE ACCEPTED (NON-EDITED) VERSION OF THE ORIGINAL STUDY TO APPEAR IN IEEE

THE PUBLISHED PAPER. COPYRIGHTS BELONG TO IEEE. https://ieeexplore.iee.org/document/9310277

left unattended. For the case of a line-fed IM, the faulty phase tends to draw a larger current, yielding an unbalanced set of phase currents, which is a fundamental indicator for the existence of an ITSC. The interaction of $I_{f}$ with the rotor flux manifests itself as a second harmonic torque component, as shown in (5), which is another primary fault signature. As the shorted turns can be assumed resistive, $\left(R_{f}+\mu R_{s} \gg \mu X_{l s}\right)$, the $I_{f}$ vector lags the stator flux linkage $\left(\Psi_{S}\right)$ vector by nearly $90^{\circ}$, since $I_{f}$ opposes the derivative of the stator flux linkage. Explanations regarding the influence of ITSC on machine dynamics will be continued in chapter IV with experimental verifications.
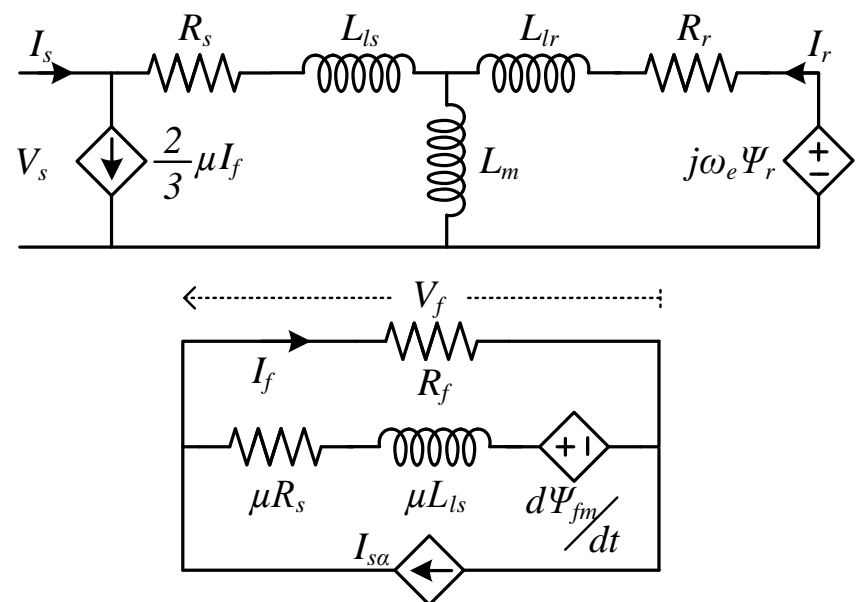

Fig. 2. Equivalent circuits for an IM with ITSC and the faulty turns.

\section{FInITE CONTROL-SET MODEL PREDICTIVE CONTROL}

This section provides the definitions of the general structure of FCS-MPC as applied to the predictive torque control of an IM. The equations that describe the control action (16)-(21) are adopted from [28],[29]. As the applied control strategy is a model-based one, the state-space model of the squirrel-cage IM should be addressed first. This is readily available from (1)-(4) by letting $R_{f} \rightarrow \infty$, hence $I_{f} \rightarrow 0$, and can be expressed as:

$$
\begin{gathered}
V_{s}=R_{s} I_{s}+\frac{d \Psi_{s}}{d t} \\
0=R_{r} I_{r}+\frac{d \Psi_{r}}{d t}-j w_{e} \Psi_{r} \\
\Psi_{s}=L_{s} I_{s}+L_{m} I_{r} \\
\Psi_{r}=L_{m} I_{s}+L_{r} I_{r}
\end{gathered}
$$

The flowchart of the FCS-MPC routine is depicted in Fig. 3. It is mainly composed of three steps: estimation, prediction, and optimization. First, the rotor and the stator fluxes are estimated by using the current measurement and the machine parameters. A suitable way for this is to use the rotor current model of the IM (14)-(15). Discrete versions of the rotor and the stator flux estimations can be obtained by Euler approximation as in (16)(17),

$$
\begin{gathered}
\frac{d \Psi_{r}}{d t}=R_{r} I_{s} \frac{L_{m}}{L_{r}}-\left(\frac{R_{r}}{L_{r}}-j w_{e}\right) \Psi_{r} \\
\Psi_{s}=\Psi_{r} \frac{L_{m}}{L_{r}}+\sigma L_{s} I_{s} \\
\Psi_{r}(k)=\Psi_{r}(k-1)+\Delta t \cdot\left(R_{r} I_{s}(k) \frac{L_{m}}{L_{r}}-\right. \\
\left.\left(\frac{R_{r}}{L_{r}}-j w_{e}(k)\right) \Psi_{r}(k-1)\right) \\
\Psi_{s}(k)=\frac{L_{m}}{L_{r}} \Psi_{r}(k)+\sigma L_{s} I_{s}(k)
\end{gathered}
$$

where $\sigma=1-L_{m}^{2} / L_{s} L_{r}$ is the leakage factor and $\Delta t$ is the control period.

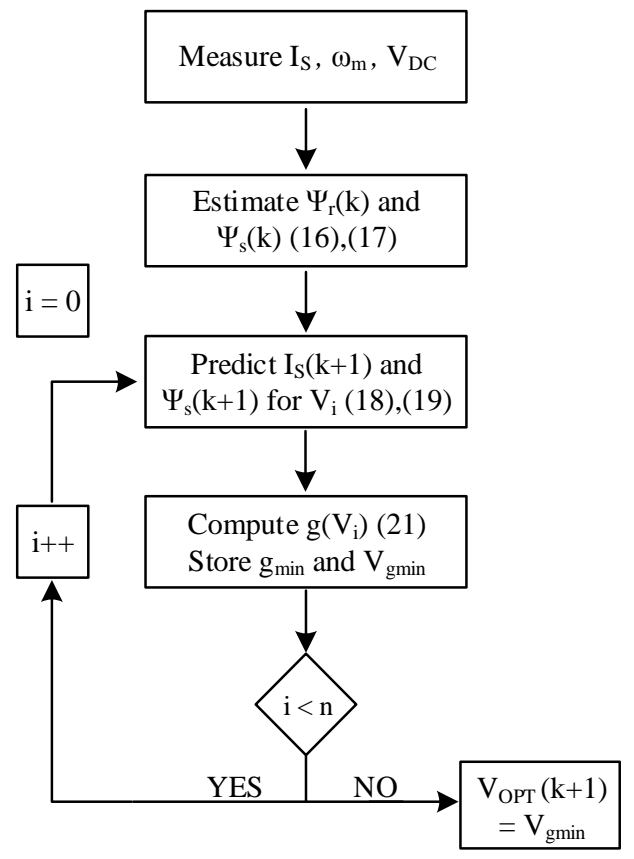

Fig. 3. A simplified flowchart diagram for the FCS-MPC routine.

Having estimated the values of $\Psi_{s}(k)$ and $\Psi_{r}(k)$, the next step in the FCS-MPC routine is to predict the values of stator flux (18), current (19) and torque (20) at the next control cycle, under the influence of a specific voltage vector $V_{i}(k)$. The superscript $p$ is used to indicate predicted variables.

$$
\begin{gathered}
\Psi_{s}^{p}(k+1)=\Psi_{s}(k)+\Delta t \cdot V_{i}(k)-\Delta t R_{s} I_{s}(k) \\
I_{s}^{p}(k+1)=\left(1-\frac{\Delta t}{\tau_{\sigma}}\right) I_{s}(k)+\frac{\Delta t}{\Delta t+\tau_{\sigma}} \\
\frac{1}{R_{\sigma}}\left(\left(\frac{k_{r}}{\tau_{r}}-k_{r} j \omega_{e}(k)\right) \Psi_{r}(k)+V_{i}(k)\right) \\
T_{e}^{p}(k+1)=1.5 p \mathfrak{I m}\left\{\Psi_{s}^{p *}(k+1) I_{s}^{p}(k+1)\right\}
\end{gathered}
$$

where, $k_{r}=L_{m} / L_{r}$ is the rotor coupling factor, $R_{\sigma}=R_{s}+$ $k_{r}^{2} R_{r}$ is the stator referred equivalent resistance, $\tau_{\sigma}=\sigma L_{s} / R_{\sigma}$ is the stator transient time constant and $\tau_{r}=\sigma L_{r} / R_{r}$ is the rotor time constant.

After the predictions for a voltage vector is obtained, the outcomes in terms of stator flux magnitude and torque can be evaluated with a cost function. This action is repeated for each 
IMPORTANT NOTE: THIS PAPER IS THE ACCEPTED (NON-EDITED) VERSION OF THE ORIGINAL STUDY TO APPEAR IN IEEE

THE PUBLISHED PAPER. COPYRIGHTS BELONG TO IEEE. https://ieeexplore.iee.org/document/9310277

admissible voltage vector, as shown in Fig. 3. While different forms for the cost function can be proposed, the conventionally used type is given in (21). A weighting factor $\lambda$ is included to adjust the relative importance of torque and flux error terms hence to tune the cost function. It is also good practice to include a penalty factor such that an infinite cost is assigned to a voltage vector if the current prediction of (19) foresees an overcurrent under the influence of that particular vector.

$$
\begin{aligned}
g=\mid T_{e}^{r e f}(k)- & T_{e}^{p}(k+1) \mid \\
& +\left.\lambda|| \Psi_{s}\right|^{r e f}-\left|\Psi_{s}^{p}(k+1)\right| \mid
\end{aligned}
$$

The voltage vector, for which the cost function of (21) yields the minimum value, is selected as the optimum and applied at the next switching instant.

\section{Closed-LOOP AND OPEN-LOOP MODES OF OPERATION WITH INTER-TURN SHORT CIRCUIT FAULTS}

Before introducing the proposed fault detection algorithm, it would be informative to consider the motoring operation with ITSC faults. An experimental comparison between open-loop and closed-loop controlled modes of operation provides essential conclusions, leading to the development of the proposed fault detection algorithms.

\section{A. The Experimental Setup}

For the development and the experimental verification of the proposed fault detection algorithm, the laboratory setup depicted in Fig. 4 is used. MPC is implemented on TMDXIDDK379D, which is an industrial motor drive development platform produced by Texas Instruments, [30]. TMDXIDDK379D includes the F28379D microcontroller [31] and a 2L-VSI with measurement and auxiliary circuits required for motor drive operation.

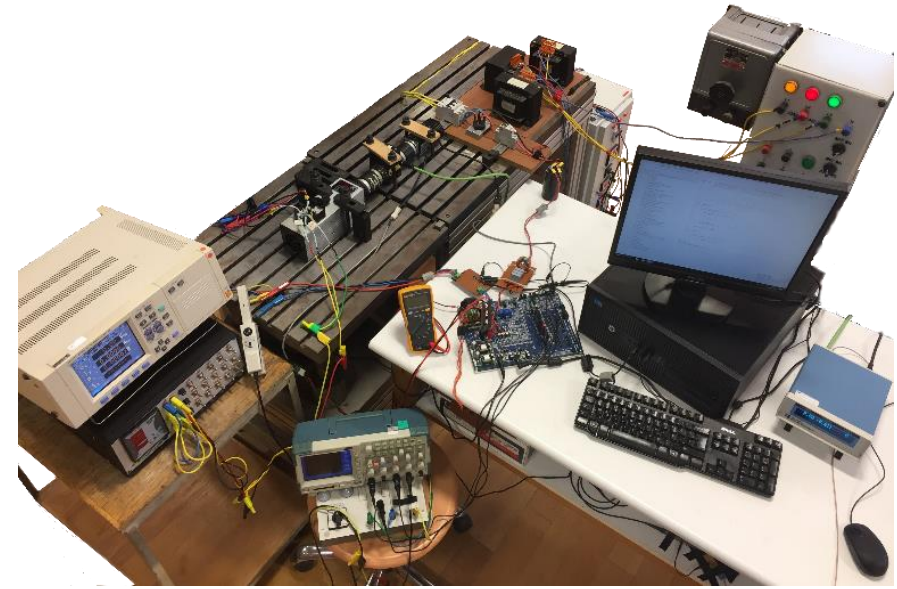

Fig. 4. A photo of the laboratory setup.

The IM on which ITSC detection algorithms have been implemented is originally designed as a spindle motor for 200 $\mathrm{Hz}$ operation. Its stator winding is custom-modified such that intentional short-circuit faults consisting of two, three, and five turns can be created. No extra resistor is utilized in ITSC tests. However, ITSCs are created over a two-meter-long cable that introduces an extra resistance of $0.35 \Omega$. The DC bus voltage of
TMDXIDDK379D, which was kept at $350 \mathrm{~V}$ throughout the experiments, and the frequency is limited with $75 \mathrm{~Hz}$. The electrical parameters and the re-defined rated values of the IM are listed in Table I.

The functional structure of the experimental setup is given in Fig. 5. The interested reader is referred to [32] for further details on the experimental implementation.

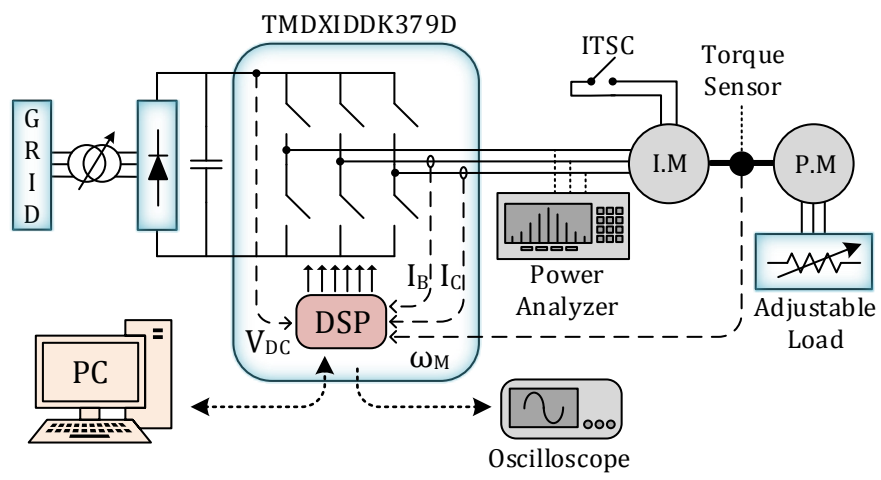

Fig. 5. The functional structure of the laboratory setup.

TABLE I

IM PARAMETERS

\begin{tabular}{lcc}
\hline \hline Name & Symbol & Value \\
\hline Power & $P$ & $500 \mathrm{~W}$ \\
Stator voltage & $V_{a b}$ & $150 \mathrm{~V}$ \\
Stator current & $I_{S}$ & $3.5 \mathrm{~A}$ \\
Base frequency & $f$ & $50 \mathrm{~Hz}$ \\
Torque & $T_{L}$ & $1.2 \mathrm{~N} . \mathrm{m}$ \\
Number of poles & $p$ & 2 \\
Number of turns in one phase & $N_{s}$ & 104 \\
Stator resistance & $R_{s}$ & $2.3 \Omega$ \\
Rotor resistance & $R_{r}$ & $3.1 \Omega$ \\
Magnetizing inductance & $L_{m}$ & $90 \mathrm{mH}$ \\
Stator leakage inductance & $L_{l s}$ & $5 \mathrm{mH}$ \\
Rotor leakage inductance & $L_{l r}$ & $1 \mathrm{mH}$ \\
Stator flux magnitude ref. & $\left|\Psi_{s}\right|^{r e f}$ & $0.4 \mathrm{~Wb}$ \\
\hline \hline
\end{tabular}

\section{B. The Influence of ITSC Fault on Current Waveforms}

A comparison of the current waveform characteristics under ITSC fault for open-loop (uncontrolled) and closed-loop (controlled) cases would provide valuable insight. The motor is both driven via the closed-loop predictive torque control and run through a fixed AC supply that matches the rated values $(150 \mathrm{~V}, 50 \mathrm{~Hz}, 1 \mathrm{~N} . \mathrm{m}$ load torque). The ITSC fault is created as the short-circuiting of three-turns at the phase-A winding. Stator current waveforms for both cases, with the fault current included, are given in Fig. 6. For the inverter driven cases (Fig. 6. c, d), the acquisition mode of the oscilloscope is set to the average of four samples. It can be observed that the faulty phase tends to draw more current, which can lead up to a $10 \%$ 
IMPORTANT NOTE: THIS PAPER IS THE ACCEPTED (NON-EDITED) VERSION OF THE ORIGINAL STUDY TO APPEAR IN IEEE

difference in magnitudes (between $\mathrm{Ch} 1$ and $\mathrm{Ch} 3$, in Fig. $6 \mathrm{a}, \mathrm{b}$ ), resulting in an unbalanced set of three-phase currents. On the other hand, the stator current waveforms for the MPC driven case are almost insensitive to the presence of an ITSC; the controller tries to create a balanced set of three-phase currents even under the influence of a fault, as shown in Fig. 6 c, d. a)

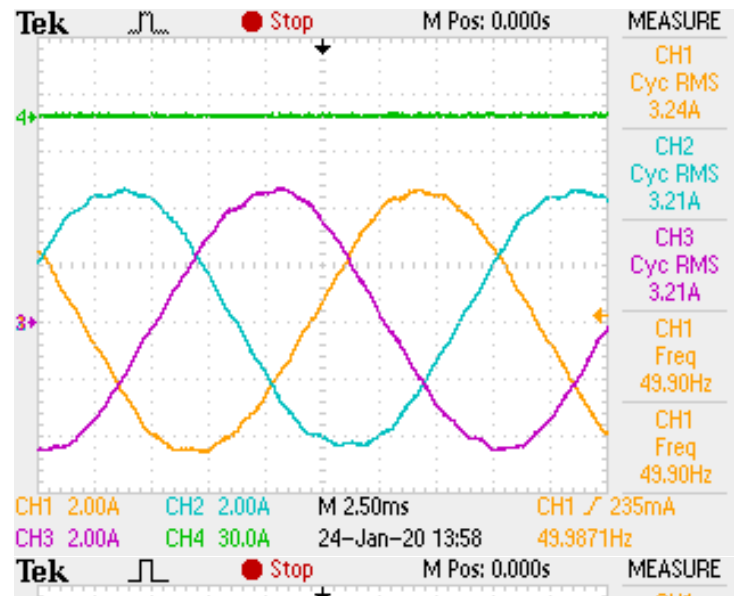

c)

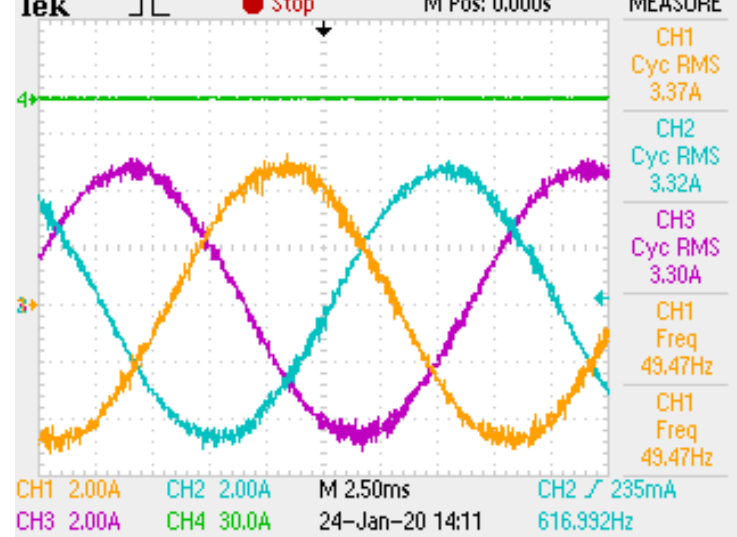

b)

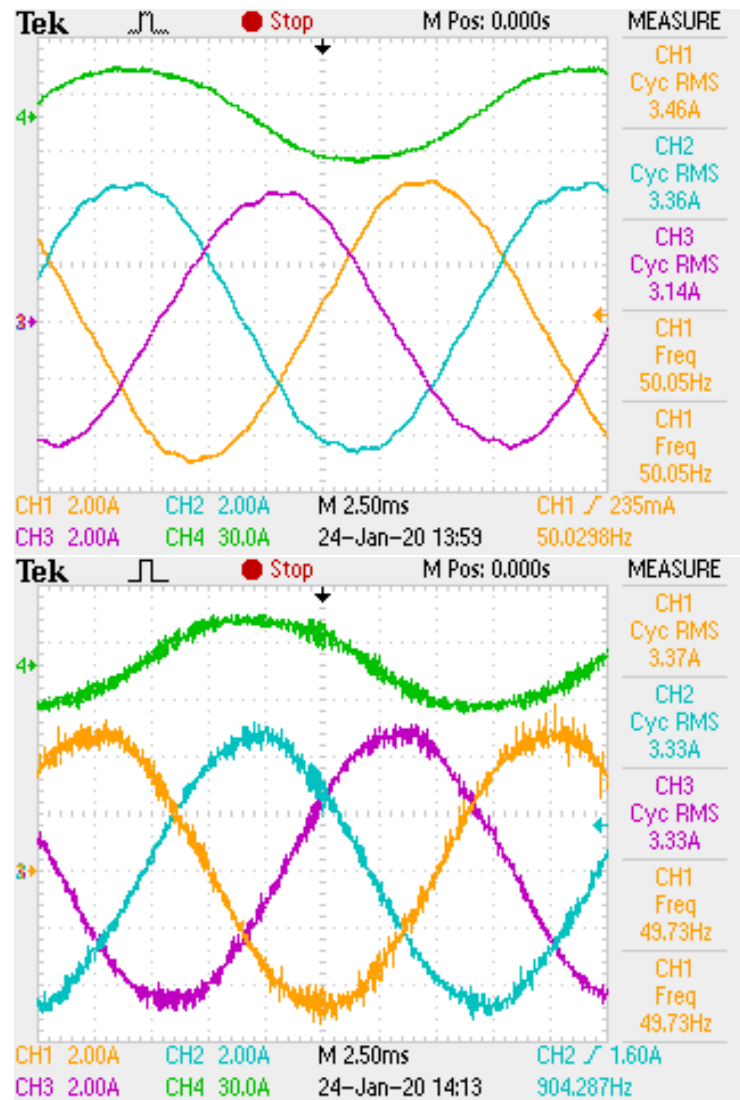

Fig. 6. Stator phase currents (Ch.1-2-3) and the ITSC current (Ch. 4) for the cases; open-loop without fault (a), open-loop with a fault (b), closed-loop without fault (c), closed-loop with a fault (d), under the operating conditions $f_{e}=50, T_{e}=1 \mathrm{~N} . \mathrm{m}$.

In the frequency domain analysis of the current waveforms, no fault-related harmonic components are observed. Similarly, the machine torque waveform does not exhibit the second harmonic pulsation. From the waveform analyzer connected to IM terminals, as shown in Fig. 5, it is observed that the line to neutral voltage of the faulty phase turns out to be approximately 1V smaller than the other phases' voltages for the closed-loop controlled case. This is the fundamental reason for the faulty phase current not increasing, contrary to the open-loop operation. We draw two important conclusions from the preceding analysis, as follows:

- Closed-loop control of a motor significantly covers the fault signatures, making waveform analysis based fault detection techniques less viable.

- For the healthy operation, the controller applies a balanced set of inverter switching vectors, which then create a balanced set of stator currents. However, for an IM with an ITSC fault on one phase, motor phases are no more identical. Therefore, under an ITSC, it is intuitive to suggest that the controller applies an unbalanced set of inverter switching vectors to yield a balanced set of stator currents.

Given the two conclusions stated above, the main idea adopted for fault detection in this paper is to investigate the controller outputs against any abnormal distribution. Evaluation of inverter switching statistics as a means for fault detection is previously proposed in [9], where the motor is driven via FOC that is accompanied by a predictive current controller. In the spatial distribution of the weighted mean values of the inverter switching vectors, two distinctive minima at $60^{\circ}$ and $240^{\circ}$ are reported as an indicator of an ITSC. In the experimental verification of the proposed ITSC detection algorithm, which is described in the following section, in addition to the decrease reported in [9], an increase in the switching vectors that correspond to the faulty phase (e.g., v1 and $\mathrm{v} 4$ for a fault in phase-A) is observed. However, having in mind that a lower value for the faulty phase voltage is created to obtain a balanced set of currents, the increase in the vectors that point into the faulty phase looks like a contradiction unless the utilization of zero-vectors is also considered.

To further investigate the influence of an ITSC on the selection of optimal switching vectors, the controller outputs are averaged and recorded for ten electrical periods, for the rated operating conditions. Adopting the classical DTC approach [33], the switching vectors are also grouped under sectors, as defined in Fig. 7, for which the stator flux vector, $\Psi_{s}$ occupies. It is observed that, under an ITSC fault, the utilization of switching vectors that correspond to the faulty phase increase 
IMPORTANT NOTE: THIS PAPER IS THE ACCEPTED (NON-EDITED) VERSION OF THE ORIGINAL STUDY TO APPEAR IN IEEE

$\left(v_{4}\right.$ during sector 3 and $v_{1}$ during sector 6) along with the utilization of zero-vectors also increasing. Therefore, the utilization of other vectors decreases and the magnitude of the applied voltage to the faulty phase is not increased due to the increase in zero-vectors. To evaluate the change in active vector allocations due to the occurrence of an ITSC fault, (22) is proposed.

$$
\Delta v_{x}=\left(\frac{v_{x}-v_{\text {avg }}}{v_{\text {avg }}}\right)_{\text {faulty }}-\left(\frac{v_{x}-v_{\text {avg }}}{v_{\text {avg }}}\right)_{\text {healthy }}
$$

By using (22), the approximated percent changes in active vectors upon fault occurrence were observed as follows: $\left(\Delta v_{1}+\Delta v_{4}\right) \cong 12 \%,\left(\Delta v_{2}+\Delta v_{5}\right) \cong-9 \%,\left(\Delta v_{3}+\Delta v_{6}\right) \cong-3 \%$.

Based on the observations discussed so far, we propose two approaches as potential ITSC fault detection methods through inverter switching statistics:

- Examination of the unbalance in the allocation of active vectors.

- Examination of the unbalance in the zero-vector allocation across the sectors of the complex plane.

ITSC fault detection has been experimentally verified for both of the methods proposed above. However, fault detection through the examination of unbalance in the active vectors was found to yield more sustainable results compared to fault detection via zero-vector allocation. Therefore, the proposed fault detection strategy, which is described and discussed in full detail in the following section, is based on active vector allocation.

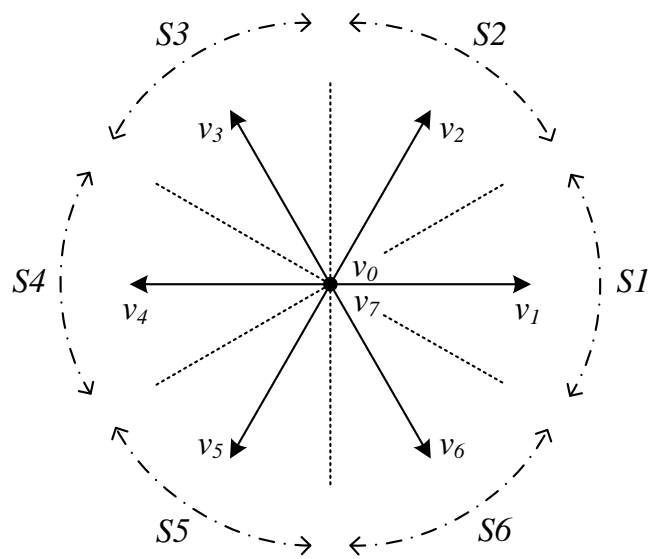

Fig. 7. Voltage vectors of a $2 \mathrm{~L}-\mathrm{VSI}$ and the sectors depicted on the complex plane.

\section{The Proposed Algorithm FOR ITSC FAUlt DETECTION}

Having identified the unexpected distribution of switching vectors as an indicator of fault's existence, the proposed method to utilize this unbalance for fault diagnosis is described in this section. Then, a series of practical issues regarding the presented fault detection strategy is discussed. Finally, a short review of the existing fault diagnosis approaches is presented, and a comparison is provided.

\section{A. Method to Evaluate the Unbalances in the MPC Output}

A flowchart diagram for the proposed fault detection algorithm is given in Fig. 8. As a simple add on to the standard
FCS-MPC structure, a counter algorithm records how many times each active vector has been chosen as the optimum by the controller. This counting routine continues for the preset number of full electrical periods (as long as 'Counter Flag' in Fig. 8 is true), which can be determined by the full rotations of the $\Psi_{s}$ vector. Once the counting process is complete, the average value of the active vector switching numbers and the percent deviation of each vector with respect to the average are calculated. Considering the influence of system non-idealities and noise on the controller action, deviations are then low-pass filtered.

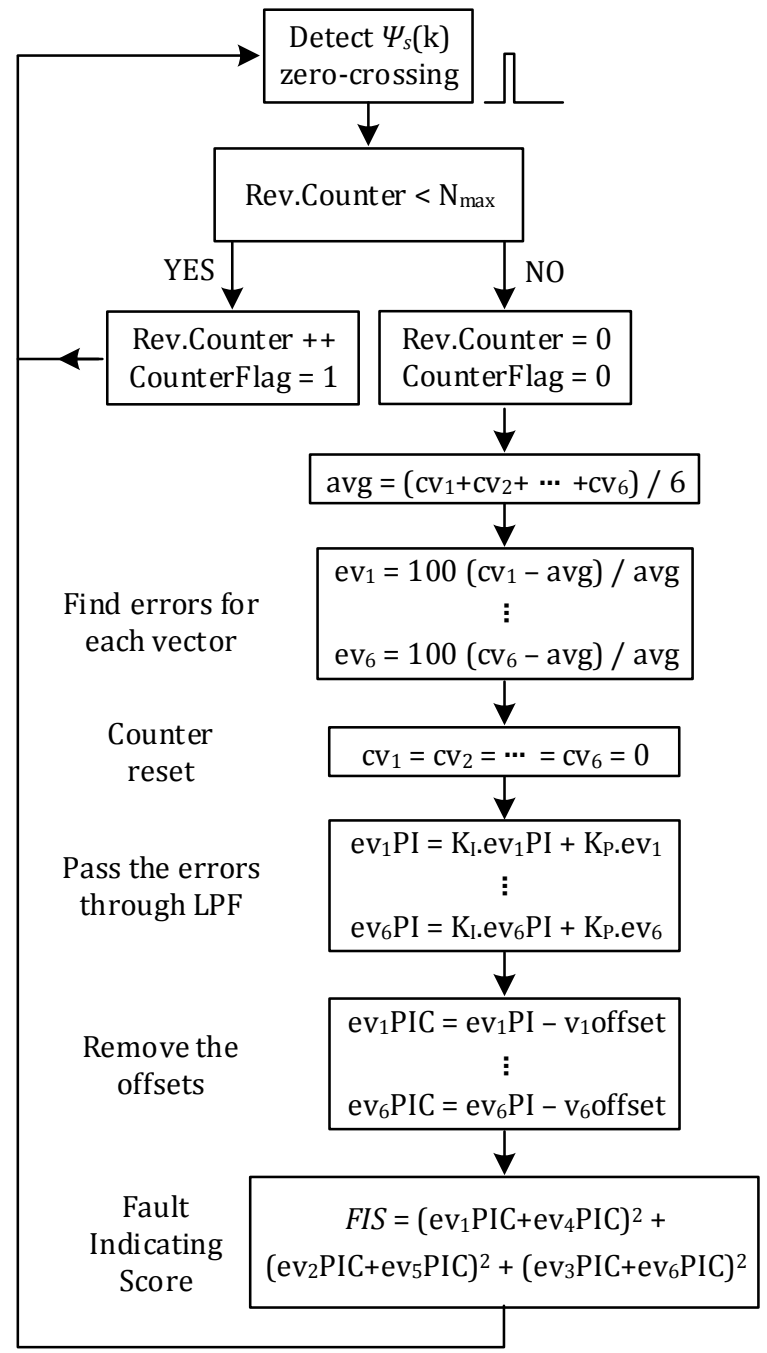

Fig. 8. Flowchart diagram of the proposed fault detection algorithm.

Since a perfect symmetry cannot be expected from a practical machine, there may be deviations in the numbers of utilization for the active vectors even under the healthy case. Although this inherent unbalance is small compared to the deviations that stem from an ITSC, the deviations in the healthy case are recorded as offset values and subtracted from the lowpass filter outputs for better fault detection performance. Finally, the filtered values of deviations are evaluated on a phase-basis, and the combined result is regarded as "the fault indicating score", abbreviated as "FIS," which can be utilized for the ultimate fault/no-fault decision. The proposed algorithm's fault detection performance is given in Fig. 9 for 
IMPORTANT NOTE: THIS PAPER IS THE ACCEPTED (NON-EDITED) VERSION OF THE ORIGINAL STUDY TO APPEAR IN IEEE

several operating values for an ITSC of two turns. The "fault indicating score" (FIS) waveform (green) exhibits a decisive increase after the ITSC is created, the instant of which is marked with a red arrow in Fig. 9. Based on the FIS, fault/no-fault decision is made (purple, high means fault). Both the FIS and the fault decision parameters are observed over the DAC pins of TMDXIDDK379D. Considering that FIS takes different values depending on the operating condition, different multipliers are utilized for better DAC visualization. The numerical value that the unit height of the oscilloscope screen corresponds is marked on the respective graphs in Fig. 9. The FIS value can be evaluated by comparison with respect to the unit height value. The results prove the effectiveness of the proposed algorithm over the entire operating range of the motor. Since the higher numbers of shorted turns produce higher FIS values; hence they are easier to diagnose, results are provided only for the two turns short-circuit case. The same fault threshold is utilized for the operating conditions in Fig. 9.

More decisive results can be obtained by utilizing a higher number of electrical periods that the vector counting routine is done $\left(N_{\max }\right.$ in Fig. 8). However, this can prolong the fault detection time. A similar trade-off exists in the design of lowpass filter parameters; fluctuations in the fault-related parameters can be avoided by low-pass filtering at the expense of delayed detection time. These parameters should be optimized for any given practical application of the proposed algorithm. For the fault detection figures depicted in Fig. 9, $N_{\text {max }}=5$ is set. The proposed fault detection method (i.e., the flowchart of Fig. 8), is run inside a $10-\mathrm{kHz}$ interrupt routine, and the computation time is measured to be $11.4 \mu \mathrm{s}$, for Rev. Counter $>N_{\max }$ case, i.e., for the complete execution of the flowchart depicted in Fig. 8.
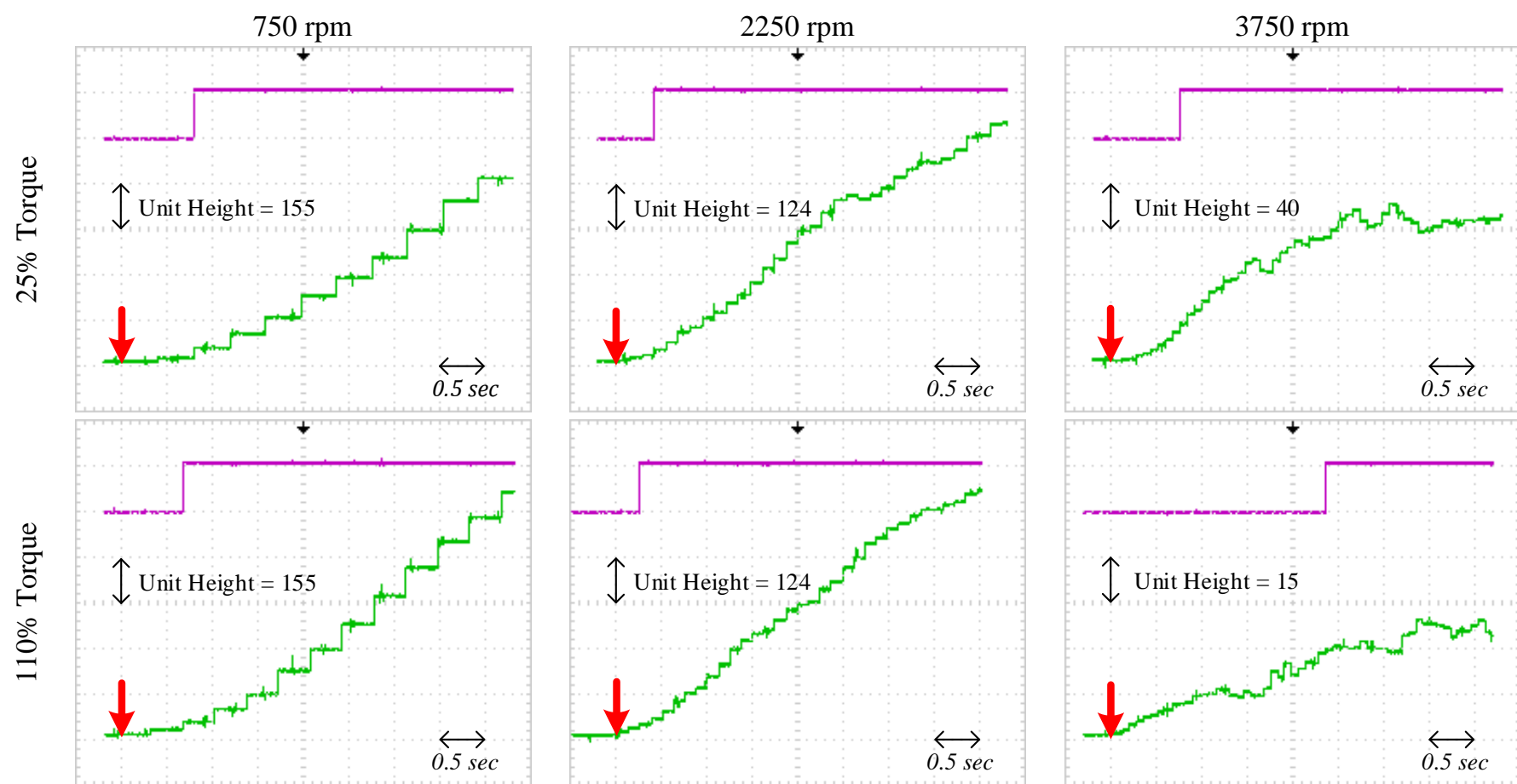

Fig. 9. The fault detection performance of the proposed algorithm, for a short-circuit of two turns, under several different operating conditions. Fault indicating score (green) and the fault/no-fault decision (purple). Fault initiation time is marked with the red arrow.

\section{B. Discussions on the Proposed Fault Detection Method}

In the following, several issues regarding the development and application of the proposed algorithm are discussed. The foremost issue worth mentioning is the generalizability of the proposed algorithm. The proposed algorithm's underlying principle is to observe for the controller outputs' unbalances as a reaction to the loss of symmetry in the machine due to the inflicting fault. Thus, other motor drive schemes, such as FOC and DTC, can also be equipped with a similar fault detection strategy. Nonetheless, model-based control techniques are more sensitive to model mismatches (which is guaranteed when driving a faulty motor); hence, they can be considered as better candidates for utilizing the proposed fault detection scheme.

We adopted FCS-MPC as the preferred motor drive technique to apply the proposed fault detection algorithm because it is intrinsically fast and flexible. Its predictive structure does not require an error term to be created and accumulated. Therefore, the disturbance in current waveforms, in which the influence of the ITSC is manifested, can be handled more effectively by the controller. On the other hand, the FOC is based on classical PI type error compensators, which have low-pass filter characteristics. The influence of the ITSC would appear as an additional AC term on the dq-quantities [6], [8], [11], which is expected to be low-pass filtered, making FOC less viable for the presented fault detection strategy. Furthermore, with FCS-MPC, it is easier to record and evaluate inverter statistics because the optimization routine outputs are discrete space-vectors in contrast to the continuous voltage references that are to be modulated, as in the case of FOC. With MPC, one has to simply count and record the cost function 
IMPORTANT NOTE: THIS PAPER IS THE ACCEPTED (NON-EDITED) VERSION OF THE ORIGINAL STUDY TO APPEAR IN IEEE

outputs to evaluate any unbalance at the inverter outputs, whereas this convenience is not present in FOC.

In FCS-MPC, the weighting factor $(\lambda)$ is a fundamental parameter that tunes the controller response. The increased value of $\lambda$ puts more emphasis on the flux magnitude error term, and implicitly improves the phase current waveform quality. Several different $\lambda$ values, ranging from 30 to 100 , have been tested. Phase current THD is near minimal for $\lambda=50(1.3 \%)$ and increasing $\lambda$ further provides little to no decrease in THD. For $\lambda<30$, the current waveforms become perceptibly distorted. The effect of $\lambda$ on the fault detection performance is also similar; although the proposed method still detects faults, smaller values of $\lambda$ makes FIS smaller. Furthermore, oscillations in FIS and discrepancies, such as different amounts of deviations for the same group of vectors (e.g., $\Delta v_{1} \neq \Delta v_{4}$ ) are observed for $\lambda \leq 30$. The results depicted in Fig. 9 are provided for $\lambda=50$.

A similar relation exists between fault detection performance and the sampling frequency. Due to the powerful microprocessor utilized in the experimental setup, the computation time for the whole FCS-MPC routine is merely 12 $\mu$ s hence a rather-high sampling frequency of $40 \mathrm{kHz}$ could be implemented. Experiments repeated with a sampling frequency of $25 \mathrm{kHz}$ still provides fault detection with decreased FIS.

It can be observed from Fig. 9 that there is an inverse relationship between motor output power and FIS. The total number of utilized zero-vectors is lower as the speed increases. Combined with a higher load torque demand that allows less margin for the change in the utilization of switching vectors, a smaller percentage of deviation occurs for high speed - high torque region.

In this paper, only the stator ITSC fault type is considered, and other fault types such as broken rotor and shaft misalignment/bearing damage lay beyond the scope. Hence, no experiments have been conducted with the proposed algorithm to detect or distinguish these types of faults. Nonetheless, these faults can be distinguished from ITSCs by their nature of occurrence. The influence of a broken rotor fault would be experienced equally by each stator phase. A bearing fault is a mechanical issue, and its rate of progression is expected to be slower than that of an ITSC. In any case, even for a wrong identification of an inflicting fault, it is beneficial to address and evaluate any unexpected operation.

The fault detection ability of the proposed algorithm under dynamic operating conditions is verified by the application of a triangular wave speed command as shown in Fig. 10.

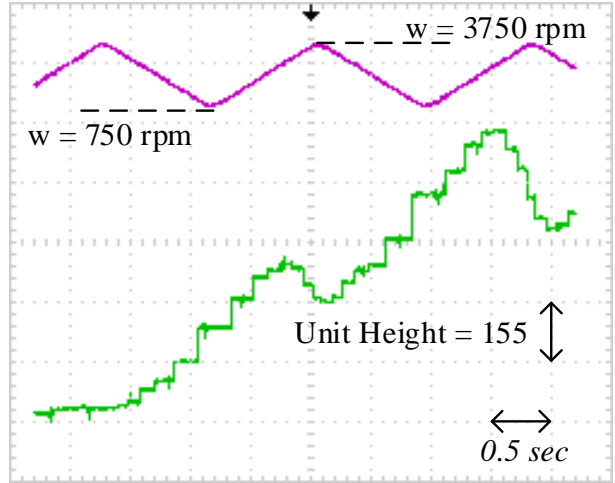

Fig. 10. The fault detection performance of the proposed algorithm under dynamic operation. Purple: motor speed in rpm. Green: fault indicating score.

For the two turns ITSC fault under rated operating conditions, the FIS waveform that is produced based on the low-pass filtered deviations of switching vectors, as illustrated in Fig. 8, is shown in Fig. 11. On the same figure, another FIS waveform, which is calculated without the low-pass filtering stage, is also shown. Although the response to the inflicting ITSC fault is much faster in the unfiltered case, the large fluctuations in the unfiltered FIS waveform can cause false triggers.

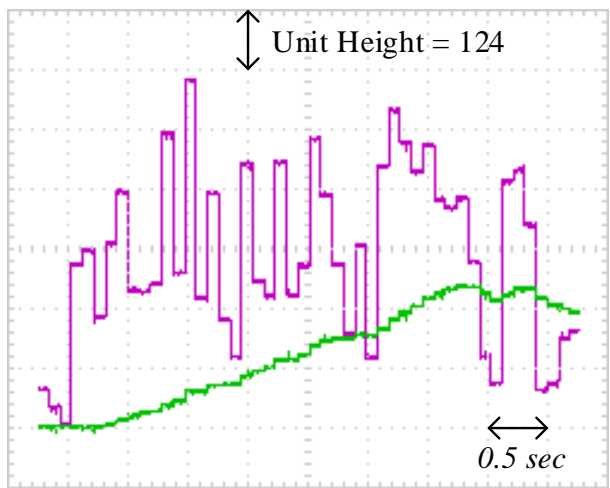

Fig. 11. The FIS waveforms; calculated from the low-pass filtered deviations (green) and the unfiltered version (purple).

As further analysis of the proposed fault detection algorithm's performance, several different FIS waveforms, five for the healthy operation at rated values case and another five for the two turns ITSC case, are depicted on the same graph, in Fig. 12. It can be seen from the figure that the algorithm is reliable as the healthy case produces FIS close to zero.

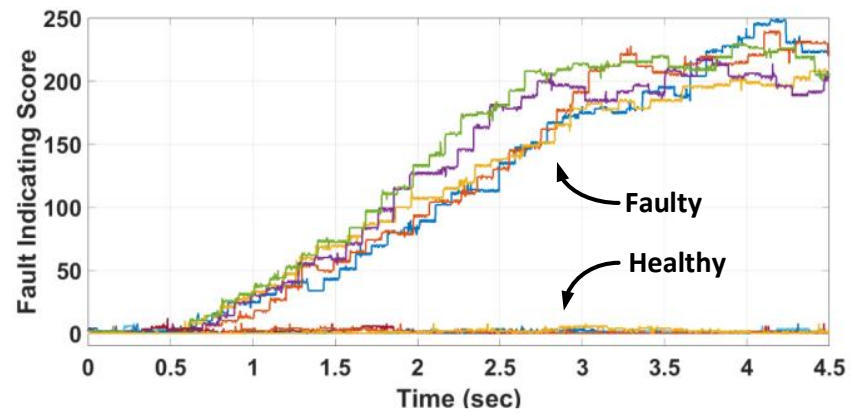

Fig. 12. Several different FIS waveforms; for both the healthy case and the two turns ITSC case under rated operating conditions. 
IMPORTANT NOTE: THIS PAPER IS THE ACCEPTED (NON-EDITED) VERSION OF THE ORIGINAL STUDY TO APPEAR IN IEEE

C. A Review on ITSC Fault Detection Schemes with ClosedLoop Control and a Comparison for the Proposed Algorithm

An exact benchmarking between any two fault diagnosis methods requires experimentation with the same machine, fault, and operating conditions; hence it is hard to realize. Nonetheless, the complete assessment of the proposed fault detection method should consider the previously suggested fault detection strategies. Therefore, several selected ITSC fault detection schemes developed for closed-loop controlled machines are compared in Table II with the proposed algorithm.

A fundamental parameter that can be utilized for benchmarking in fault diagnosis methods would be the severity factor $(\mu)$, which was defined as the ratio of the shorted turns to the total number of turns in the phase $\left(\mu=N_{f} / N_{p h}\right)$. With the proposed method, two shorted turns (out of 104 turns in a phase) is detected $(\mu=1.9 \%)$, which can be considered quite satisfactory among the other methods presented in Table II. It should be noted that the severity ratios may differ in some of the papers cited in Table II, due to the adoption of different definitions for the severity ratio, as in [11] and [14]. Furthermore, additional fault resistances may or may not be utilized, and the physical structures of the artificial faults created for the experiments would differ. Therefore, the severity factor alone should not be regarded as an ultimate quality figure. A single-turn fault option was not made available in the experimental IM; hence this case could not be tested. FIS waveforms obtained for the two turns fault in Fig. 9 suggest that a single-turn fault could have been detected too, at least for the low to medium speed region.

TABLE II

A Review of Existing Fault Diagnosis Methods That Consider Closed-LoOP CONTROLLED MACHINES

\begin{tabular}{clcl}
\hline \hline Ref. & $\begin{array}{c}\text { Motor Type \& } \\
\text { Control Method }\end{array}$ & $\begin{array}{c}\text { Severity }(\%) \\
\left(\mu=N_{f} / N_{p h}\right)\end{array}$ & Detection Method \\
\hline$[5]$ & PMSM, FOC & 9.85 & Freq.-Domain Analysis \\
{$[6]$} & IM, FOC & 8.33 & Freq.-Domain Analysis \\
{$[7]$} & IM, FOC & 0.93 & Freq.-Domain Analysis \\
{$[8]$} & IM, FOC & 0.32 & Freq.-Domain Analysis \\
{$[9]$} & IM, FOC+PCC & 0.76 & Inverter Statistics \\
{$[10]$} & PMSM, FOC & 3.23 & PWM Ripple \\
{$[11]$} & PMSM, FOC & 1.39 & Freq.-Domain Analysis \\
{$[12]$} & PMSM, FOC & 2.78 & Time-Freq. Distribution \\
{$[13]$} & IM, FOC & 0.30 & High Freq. Injection \\
{$[14]$} & IM, DTC & 1.08 & Freq.-Domain Analysis \\
{$[15]$} & IM, DTC & 2.04 & Freq.-Domain Analysis \\
[16] & PMSM, & 5.00 & $\begin{array}{l}\text { Wavelet Transform on } \\
\text { FCS-MPC }\end{array}$ \\
\hline \hline
\end{tabular}

It can be concluded from Table II that; frequency domain analysis is the favored strategy for fault detection. In most papers, fault detection has been reduced to addressing unexpected frequency components that would otherwise diminish for a healthy machine. This can be addressed as a major simplification in the respective studies because making the final decision is whole another algorithm to be implemented and tuned. A faulty/healthy decision, as shown in Fig. 9 of this paper, is presented only in [11].

In this paper, the proposed fault detection algorithm is tested for several different speed and load torque levels where fault detection performance for a wide torque-speed range was documented only in a limited number of studies ([5], [7], [8], [11]) from Table II. Similarly, fault detection performance under dynamic operating conditions is depicted in Fig. 10 of this study, where only [12] considers the dynamic case, among the references of Table II.

Publications on fault diagnostics almost unanimously express how critical it is to detect a fault as soon as possible to avoid catastrophic damage. Considering the rate of progression of an ITSC fault, it is very interesting to see that fault detection time is explicitly mentioned only in [13]. The elapsed time between fault's occurrence and detection is reported below two seconds in [13], which is roughly equal to the detection times of this paper, which can be observed from Fig. 9 .

Among the fault diagnosis algorithms listed in Table II, details regarding the microcontroller on which the fault detection algorithm is implemented and the computational burden brought by its application are virtually non-existent. The ITSC detection strategy presented in this paper runs on the same CPU alongside the FCS-MPC routine. The total time spent on the full execution of the flowchart depicted in Fig. 8 is measured to be $11.4 \mu \mathrm{s}$. The algorithm is very intuitive, and it is straightforward to be implemented as a simple add-on to the standard FCS-MPC structure. The proposed algorithm is online and non-evasive. Neither an additional circuit (as in [10]) nor an external sensor (as in [14]) is required.

\section{CONCLUSION}

Fault diagnosis of electric motors becomes more complicated for the case of inverter-driven, closed-loop controlled applications because the controller inherently tries to create a balanced set of current even under the faulty conditions. In this paper, a novel stator inter-turn short detection algorithm is developed, which detects and identifies the short-circuit fault based on the unexpected deviations in the active vector allocations. The proposed algorithm is intuitive, non-invasive, and works as a simple extension to the FCS-MPC routine without any significant computational burden. In the experimental verification, short-circuits of two turns are effectively detected and located for a $500 \mathrm{~W}$ induction machine, in both steady-state and dynamic operating conditions. 


\section{REFERENCES}

[1] S. Nandi, H. A. Toliyat, and X. Li, "Condition Monitoring and Fault Diagnosis of Electrical Motors-A Review," IEEE Trans. Energy Convers., vol. 20, no. 4, pp. 719-729, Dec. 2005.

[2] A. Bellini, F. Filippetti, C. Tassoni, and G. A. Capolino, "Advances in diagnostic techniques for induction machines," IEEE Trans. Ind. Electron., vol. 55, no. 12, pp. 4109-4126, 2008.

[3] G. S. Yadava, B. Singh, and A. Siddique, "A Review of Stator Fault Monitoring Techniques of Induction Motors," IEEE Trans. Energy Convers., vol. 20, no. 1, pp. 106-114, 2005.

[4] A. Gandhi, T. Corrigan, and L. Parsa, "Recent advances in modeling and online detection of stator interturn faults in electrical motors," IEEE Trans. Ind. Electron., vol. 58, no. 5, pp. 1564-1575, 2011.

[5] M. Zafarani, E. Bostanci, Y. Qi, T. Goktas, and B. Akin, "Interturn shortcircuit faults in permanent magnet synchronous machines: An extended review and comprehensive analysis," IEEE J. Emerg. Sel. Top. Power Electron., vol. 6, no. 4, pp. 2173-2191, 2018.

[6] A. Bellini, F. Filippetti, G. Franceschini, and C. Tassoni, "Closed-Loop Control Impact on the Diagnosis of Induction Motors Faults," IEEE Trans. Ind. Appl., vol. 36, no. 5, pp. 1318-1329, 2000.

[7] S. Cheng, S. Member, P. Zhang, and T. G. Habetler, "An Impedance Identification Approach to Sensitive Detection and Location of Stator Turn-to-Turn Faults in a Closed-Loop Multiple-Motor Drive," IEEE Trans. Ind. Electron., vol. 58, no. 5, pp. 1545-1554, 2011.

[8] M. Wolkiewicz, G. Tarchała, T. Orłowska-Kowalska, and C. T. Kowalski, "Online stator interturn short circuits monitoring in the DFOC induction-motor drive," IEEE Trans. Ind. Electron., vol. 63, no. 4, pp. 2517-2528, Apr. 2016.

[9] T. M. Wolbank, K. A. Loparo, and R. Wohrnschimmel, "Inverter statistics for online detection of stator asymmetries in inverter-fed induction motors," IEEE Trans. Ind. Appl., vol. 39, no. 4, pp. 11021108, Jul. 2003.

[10] B. Sen and J. Wang, "Stator Interturn Fault Detection in PermanentMagnet Machines Using PWM Ripple Current Measurement," IEEE Trans. Ind. Electron., vol. 63, no. 5, pp. 3148-3157, 2016.

[11] K. H. Kim, "Simple online fault detecting scheme for short-circuited turn in a PMSM through current harmonic monitoring," IEEE Trans. Ind. Electron., vol. 58, no. 6, pp. 2565-2568, 2011.

[12] J. A. Rosero, L. Romeral, J. A. Ortega, and E. Rosero, "Short-circuit detection by means of empirical mode decomposition and Wigner-Ville distribution for PMSM running under dynamic condition," IEEE Trans. Ind. Electron., vol. 56, no. 11, pp. 4534-4547, 2009.

[13] F. Briz, M. W. Degner, A. Zamarrón, and J. M. Guerrero, "Online Stator Winding Fault Diagnosis in Inverter-Fed AC Machines using HighFrequency Signal Injection," IEEE Trans. Ind. Appl., vol. 39, no. 4, pp. 1109-1117, 2003

[14] H. H. Eldeeb, A. Berzoy, and O. Mohammed, "Stator Fault Detection on DTC-Driven IM via Magnetic Signatures Aided by 2-D FEA CoSimulation," IEEE Trans. Magn., vol. 55, no. 6, pp. 1-5, Jun. 2019.

[15] S. M. A. Cruz and A. J. M. Cardoso, "Diagnosis of stator inter-turn short circuits in DTC induction motor drives," IEEE Trans. Ind. Appl., vol. 40, no. 5, pp. 1349-1360, 2004.

[16] J. Hang, J. Zhang, M. Xia, S. Ding, and W. Hua, "Interturn Fault Diagnosis for Model-Predictive-Controlled-PMSM Based on Cost Function and Wavelet Transform," IEEE Trans. Power Electron., vol. 35, no. 6, pp. 6405-6418, 2020.

[17] S. Vazquez, J. Rodriguez, M. Rivera, L. G. Franquelo, and M. Norambuena, "Model Predictive Control for Power Converters and Drives: Advances and Trends," IEEE Trans. Ind. Electron., vol. 64, no. 2, pp. 935-947, Feb. 2017.

[18] S. Kouro, P. Cortes, R. Vargas, U. Ammann, and J. Rodriguez, "Model Predictive Control-A Simple and Powerful Method to Control Power Converters," IEEE Trans. Ind. Electron., vol. 56, no. 6, pp. 1826-1838, Jun. 2009.

[19] S. Vazquez et al., "Model Predictive Control: A Review of Its Applications in Power Electronics," IEEE Ind. Electron. Mag., vol. 8, no. 1, pp. 16-31, Mar. 2014.

[20] J. Rodriguez et al., "State of the Art of Finite Control Set Model Predictive Control in Power Electronics," IEEE Trans. Ind. Informatics, vol. 9, no. 2, pp. 1003-1016, May 2013.

[21] S. Kouro, M. A. Perez, J. Rodriguez, A. M. Llor, and H. A. Young, "Model Predictive Control: MPC's Role in the Evolution of Power Electronics," IEEE Ind. Electron. Mag., vol. 9, no. 4, pp. 8-21, 2015.

[22] O. V. Thorsen and M. Dalva, "A survey of faults on induction motors in offshore oil industry, petrochemical industry, gas terminals and oil refineries," IEEE Trans. Ind. Appl., vol. 31, no. 5, pp. 1186-1196, 1995.

[23] A. H. Bonnett and C. Yung, "Increased efficiency versus increased reliability," IEEE Ind. Appl. Mag., vol. 14, no. 1, pp. 29-36, 2008.

[24] R. M. Tallam, T. G. Habetler, and R. G. Harley, "Transient model for induction machines with stator winding turn faults," IEEE Trans. Ind. Appl., vol. 38, no. 3, pp. 632-637, 2002.

[25] X. Chang, V. Cocquempot, and C. Christophe, "A model of asynchronous machines for stator fault detection and isolation," IEEE Trans. Ind. Electron., vol. 50, no. 3, pp. 578-584, 2003.

[26] A. Berzoy, A. A. S. Mohamed, and O. Mohammed, "Complex-Vector Model of Interturn Failure in Induction Machines for Fault Detection and Identification," IEEE Trans. Ind. Appl., vol. 53, no. 3, pp. 2667-2678, 2017.

[27] D. C. Patel and M. C. Chandorkar, "Modeling and analysis of stator interturn fault location effects on induction machines," IEEE Trans. Ind. Electron., vol. 61, no. 9, pp. 4552-4564, 2014.

[28] M. Habibullah, D. D.-C. Lu, D. Xiao, and M. F. Rahman, "A Simplified Finite-State Predictive Direct Torque Control for Induction Motor Drive," IEEE Trans. Ind. Electron., vol. 0046, no. c, pp. 1-1, 2016.

[29] J. Rodriguez and P. Cortes, Predictive Control of Power Converters and Electrical Drives. John Wiley \& Sons, Ltd, 2012.

[30] R. Ramamoorthy, B. Larimore, and M. Bhardwaj, "Sensored Field Oriented Control of 3-Phase Permanent Magnet Synchronous Motors using F2837x," 2016.

[31] Texas Instruments, "TMS320F2837xD Dual-Core Delfino TM Microcontrollers," 2018.

[32] İ. Sahin and O. Keysan, "A simplified discrete-time implementation of FCS-MPC applied to an IM drive," in 21st European Conference on Power Electronics and Applications, EPE ECCE Europe, 2019, pp. 1-8.

[33] I. Takahashi and T. Noguchi, "A New Quick-Response and HighEfficiency Control Strategy of an Induction Motor," IEEE Trans. Ind. Appl., vol. IA-22, no. 5, pp. 820-827, 1986.

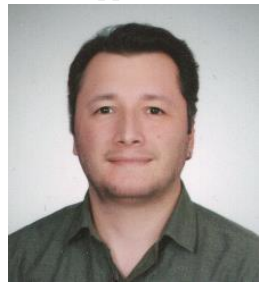

İlker Şahin (S'18) was born in Karabük, Turkey, in 1986. He received the B.Sc. and M.Sc. degrees in electrical and electronics engineering in 2010 and 2014, respectively, from Middle East Technical University (METU), Ankara, Turkey. He is currently working toward his Ph.D. degree in electrical and electronics engineering at the same department.

After his employment as a teaching assistant at METU since 2011, he joined Aselsan in 2020, as a lead design engineer. His current research interests include motor drives, predictive control, and fault diagnosis.

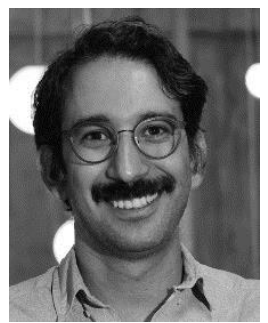

Ozan Keysan received the master's degree from Middle East Technical University (METU), Ankara, Turkey, in 2008, and the Ph.D. degree from the University of Edinburgh, Edinburgh, Scotland, in 2014.

He is currently an Assistant Professor with the Electrical and Electronics Engineering Department, METU. His current research interests include renewable energy, design, and optimization of electrical machines, smart grids, superconducting machines, and permanent-magnet machines. 